Supplement of

\title{
Relating large-scale subsidence to convection development in Arctic mixed-phase marine stratocumulus
}

\section{Gillian Young et al.}

Correspondence to: Thomas W. Choularton (choularton@manchester.ac.uk) and Gillian Young (giyoung@bas.ac.uk)

The copyright of individual parts of the supplement might differ from the CC BY 4.0 License. 


\section{Supplementary Material}
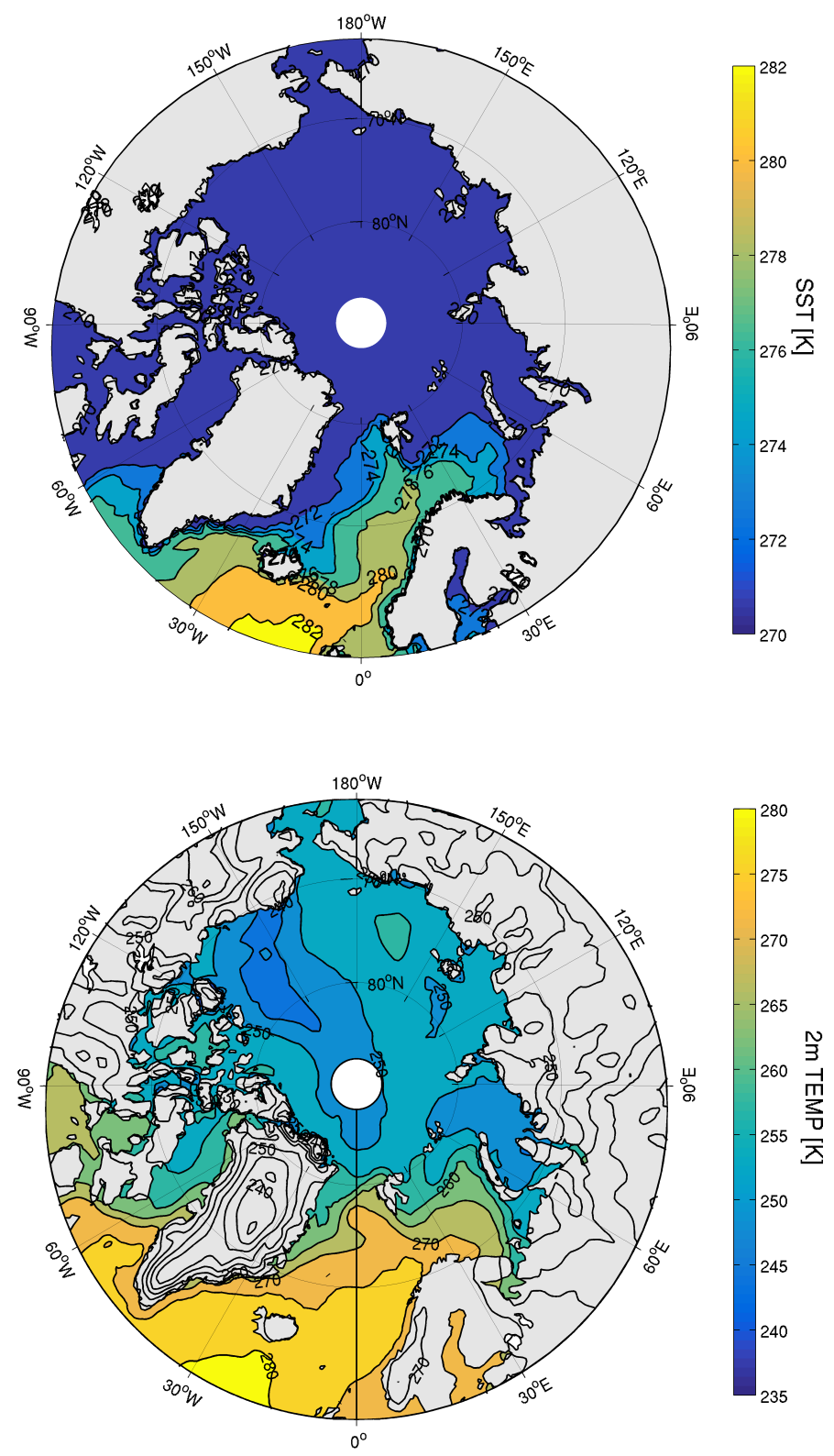

Figure S1. ERA-Interim (ECMWF Reanalysis, Dee et al., 2011) data for sea surface temperature (SST, top panel) and $2 \mathrm{~m}$ temperature (bottom panel) on 23 March 2013. These data were used as a guide to construct a surface warming profile. Data used to initialise the LEM from Young et al. (2017) - were simulated on this day. 

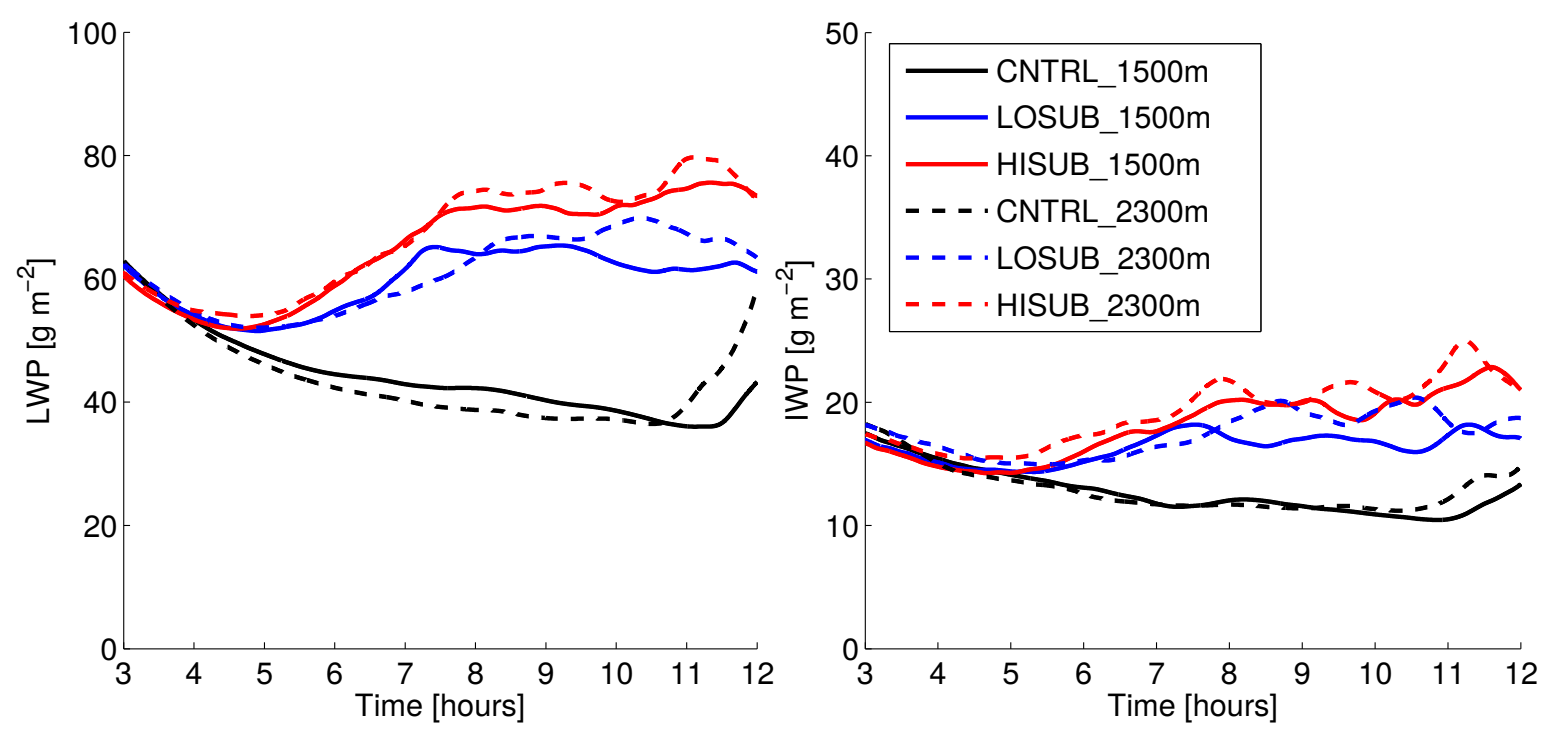

Figure S2. Domain-averaged liquid- and ice-water path time series for the runs detailed in test 1 (solid lines) and those with more $\mathrm{Z}$ levels added (dashed lines). Runs listed with the suffix _ $2300 \mathrm{~m}$ have more vertical levels added: $20 \mathrm{~m}$ resolution is imposed up to $2300 \mathrm{~m}$, above which it decreases to $50 \mathrm{~m}$. The trends identified in Sect. 3.1 (greater LWP/IWP with imposed subsidence) are largely unaffected by the addition of more high resolution levels across the BL inversion. 


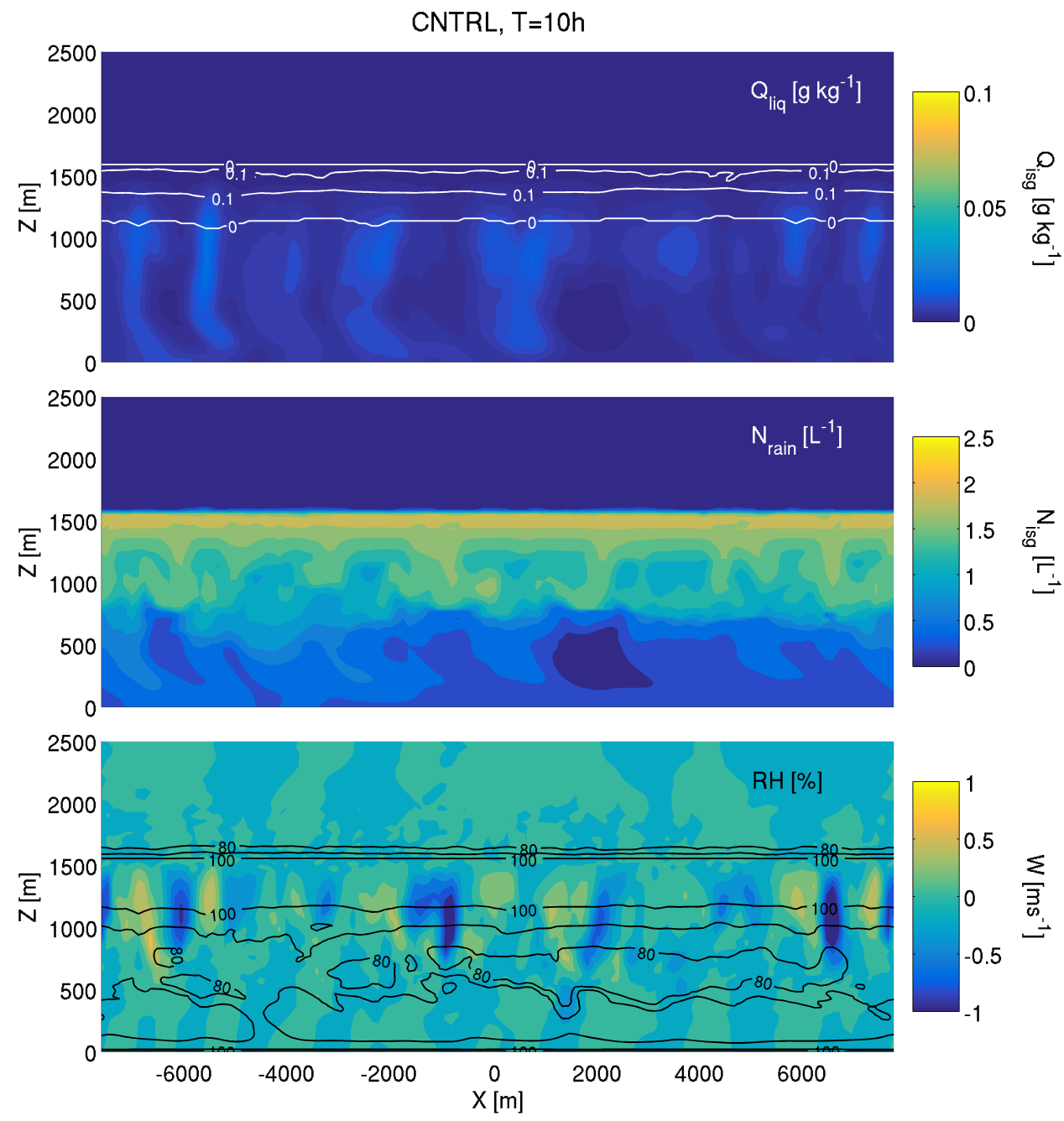

Figure S3. Z-X slices for the CNTRL case at $10 \mathrm{~h}$. Top row: total ice mass mixing ratio $\left(\mathrm{Q}_{\mathrm{isg}}\right.$, shading) and liquid water mass mixing ratio ( $\mathrm{Q}_{\text {liq }}$, contours). Middle row: total ice number concentration ( $\mathrm{N}_{\mathrm{isg}}$, shading) and rain number concentration ( $\mathrm{N}_{\text {rain }}$, contours). Bottom row: vertical velocity ( $\mathrm{W}$, shading) and relative humidity $(\mathrm{RH}$, contours). 


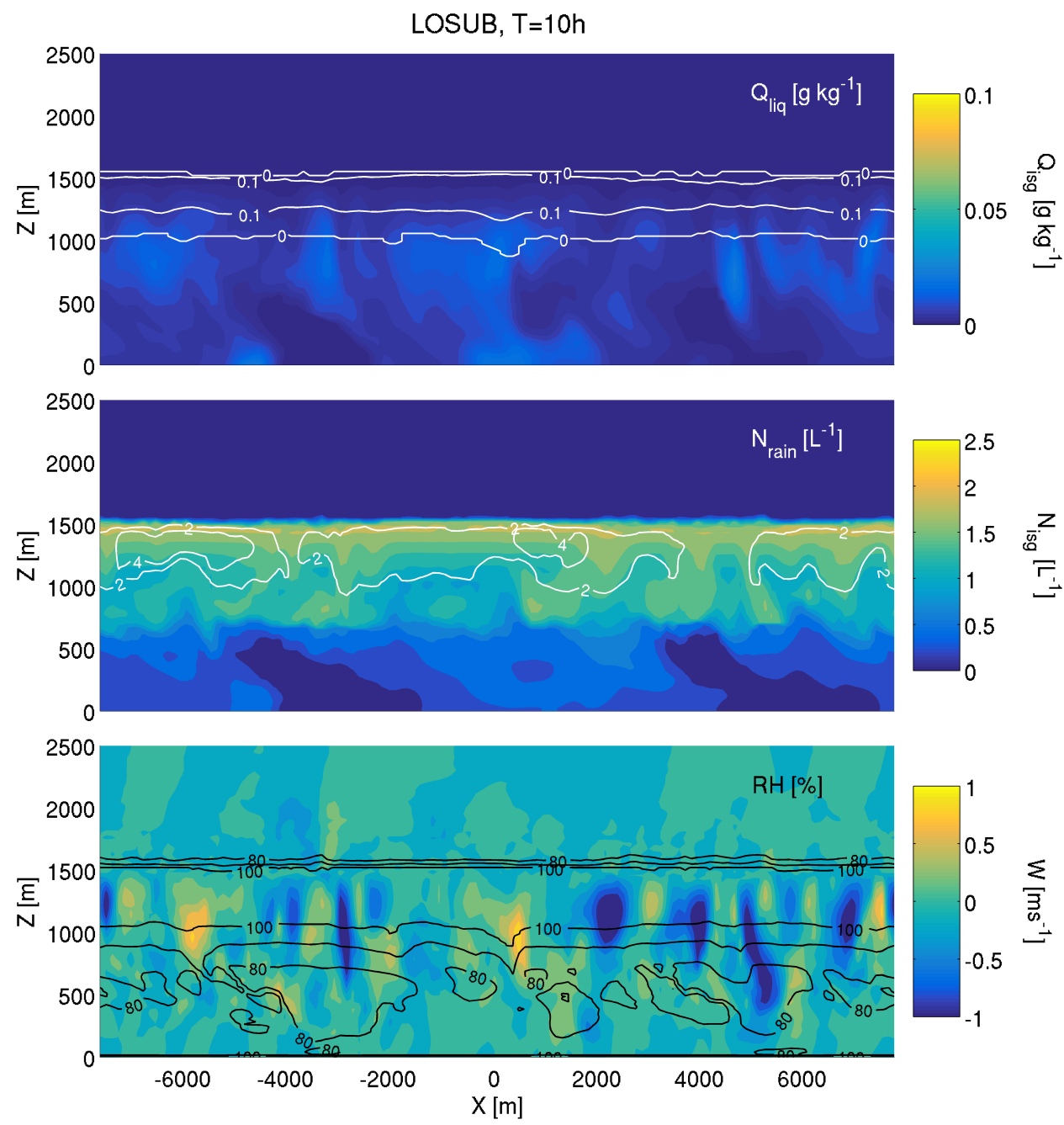

Figure S4. Z-X slices for the LOSUB case at $10 \mathrm{~h}$, mirroring the format of Fig. S3. 


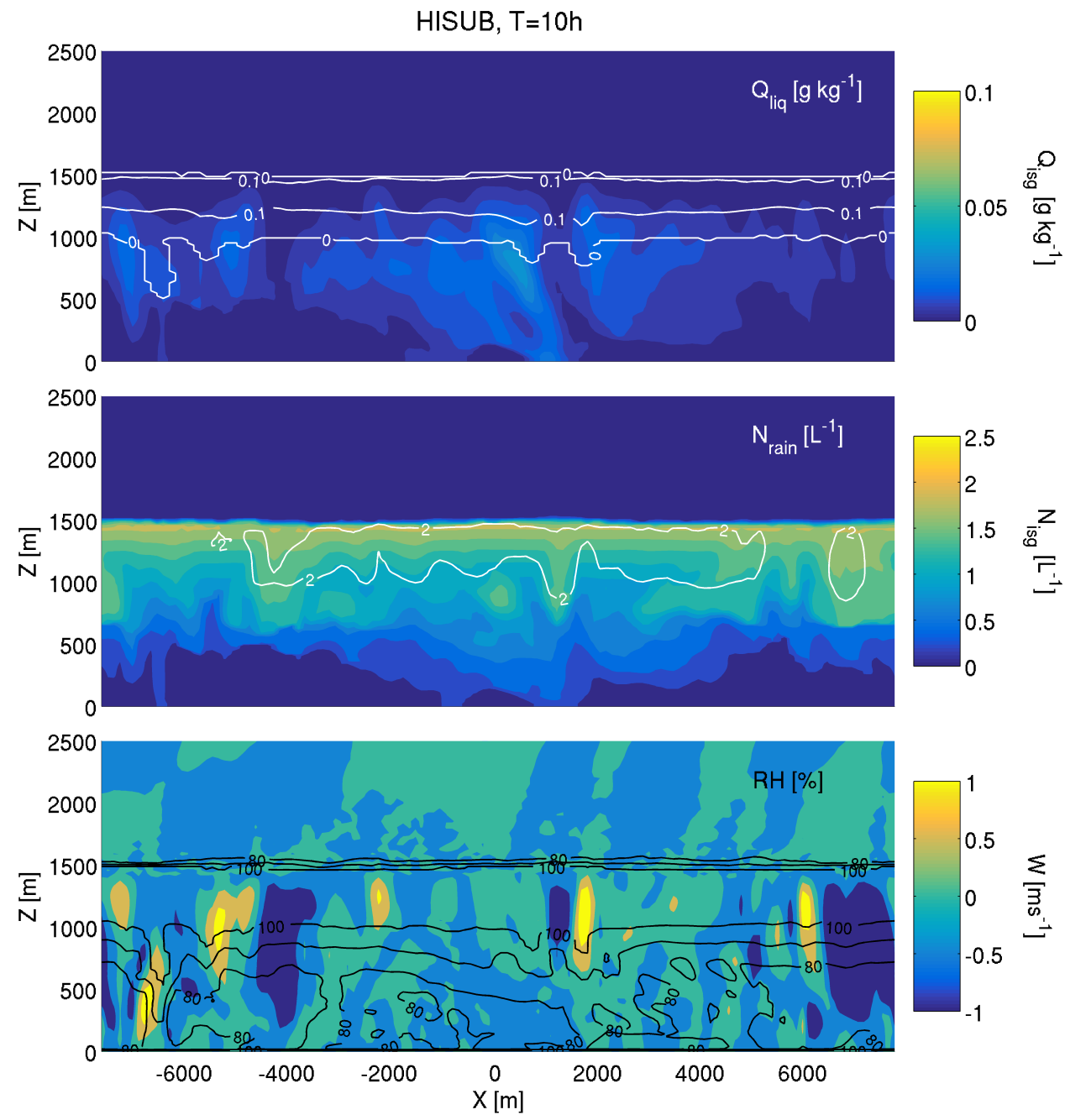

Figure S5. Z-X slices for the HISUB case at $10 \mathrm{~h}$, mirroring the format of Fig. S3. In panel (c), strong updraughts and downdraughts are evident, with particularly broad downdraught regions. Pools of heightened RH occur at the bottom of these downdraught regions, co-located with elongated regions of $\mathrm{N}_{\text {rain }}$ in the Sc layer above. 


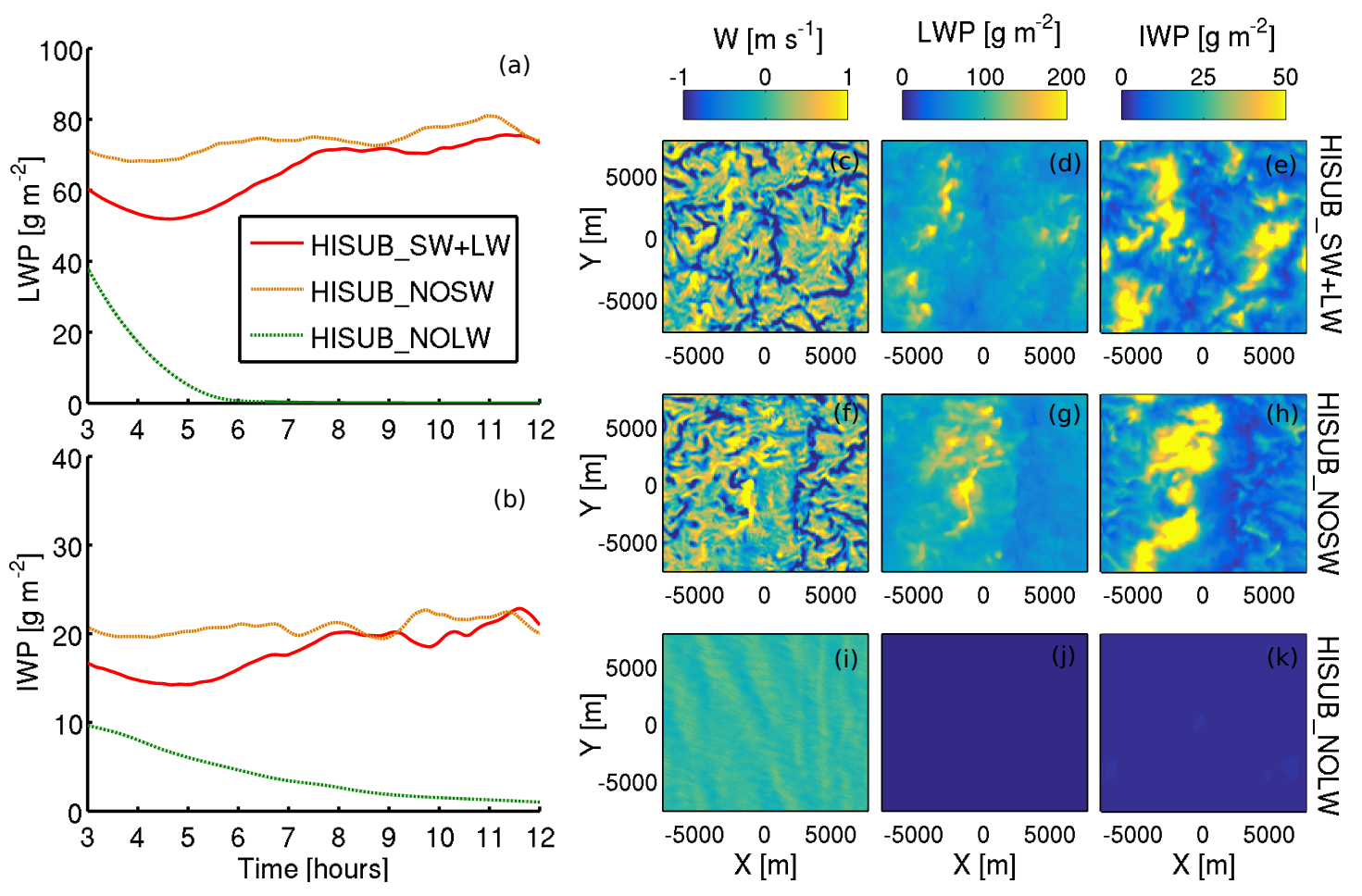

Figure S6. Relationship between subsidence-induced convection and radiation. (a, b): Time series of the domain-averaged LWP and IWP from HISUB simulations with both shortwave (SW) and longwave (LW) switched on (red), only LW on (orange), and only SW on (green). (c-k): Planar X-Y views of (c,f,j) vertical velocity, W, at $1000 \mathrm{~m},(\mathbf{d}, \mathbf{g}, \mathbf{j})$ LWP, and (e,h,k) IWP. Planar views shown at $11 \mathrm{~h}$. Cloud lifetime is strongly dependent on longwave radiative cooling being represented in the model; dissipation occurs quickly in its absence. Likewise, cloud heating by shortwave (solar) radiation is important to allow the development of the closed-cellular structure shown in panel c. Longwave radiative cooling at cloud top plays an important role in development of convection in the subsidence cases shown. 

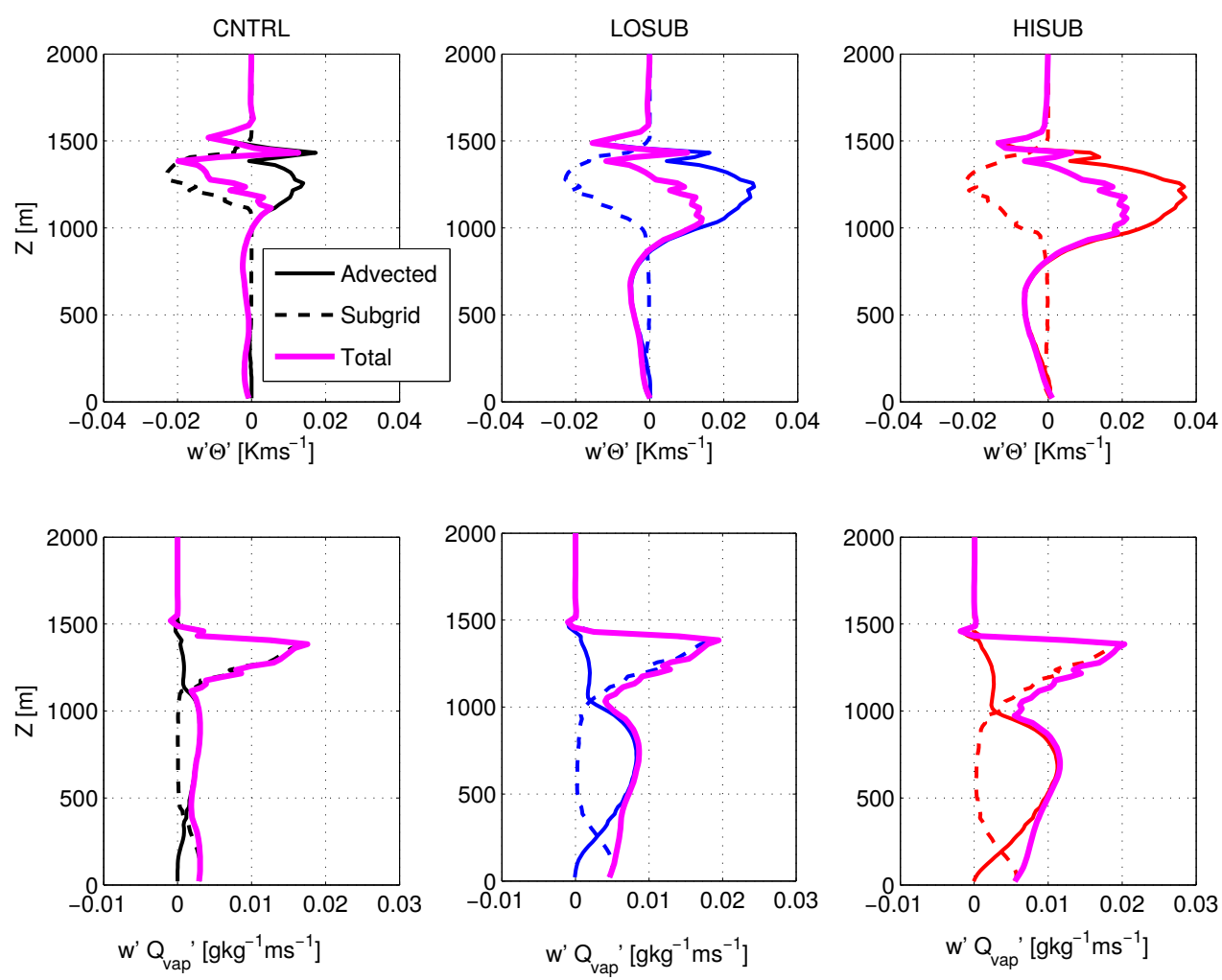

Figure S7. Relative contribution of advected (solid) and sub-grid (dashed) fluxes to the total (solid, magenta), w' $\Theta^{\prime}$ (top row), and w' $\mathrm{Qvap}^{\prime}$ at $9 \mathrm{~h}$ in test 1. 

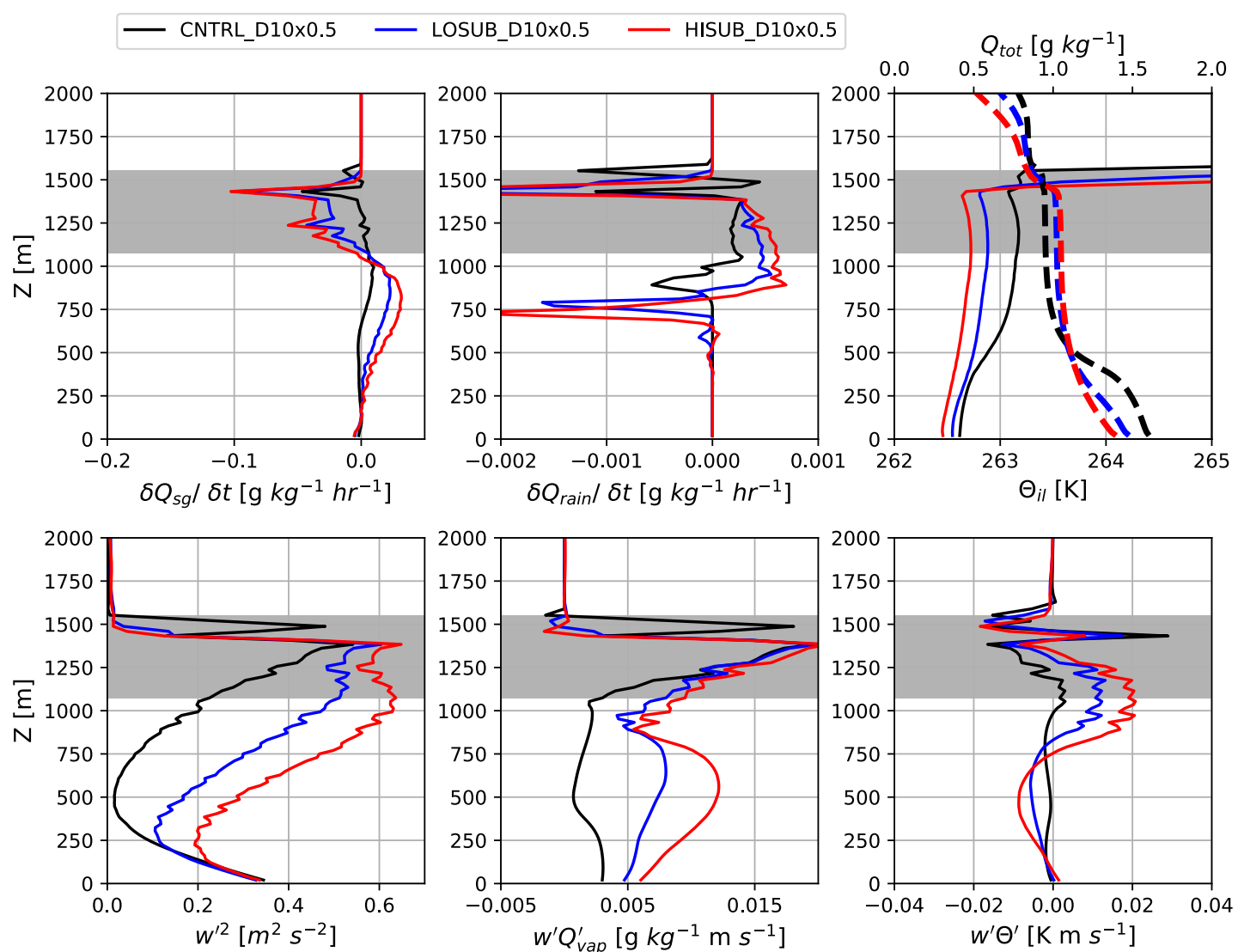

Figure S8. Vertical profiles, at $9 \mathrm{~h}$, of solid precipitation (snow + graupel) mass tendency, rain mass tendency $\left(\delta \mathrm{Q}_{\text {rain }} / \delta \mathrm{t}\right.$ ), ice-liquid potential temperature $\left(\Theta_{\mathrm{il}}\right.$, solid) and total water mixing ratio $\left(\mathrm{Q}_{\mathrm{tot}}\right.$, dashed), vertical velocity variance $\left(\mathrm{w}^{\prime 2}\right)$, vertical flux of water vapour ( $\mathrm{w}^{\prime} \mathrm{Q}_{\mathrm{vap}}$ ') and buoyancy flux ( $\left.w^{\prime} \Theta^{\prime}\right) . w^{\prime 2}, w^{\prime} Q_{v a p}$ ', and w' $\Theta^{\prime}$ are total quantities (sub-grid + advected). Area in grey represents CNTRL_D10x0.5 cloudy regions. 

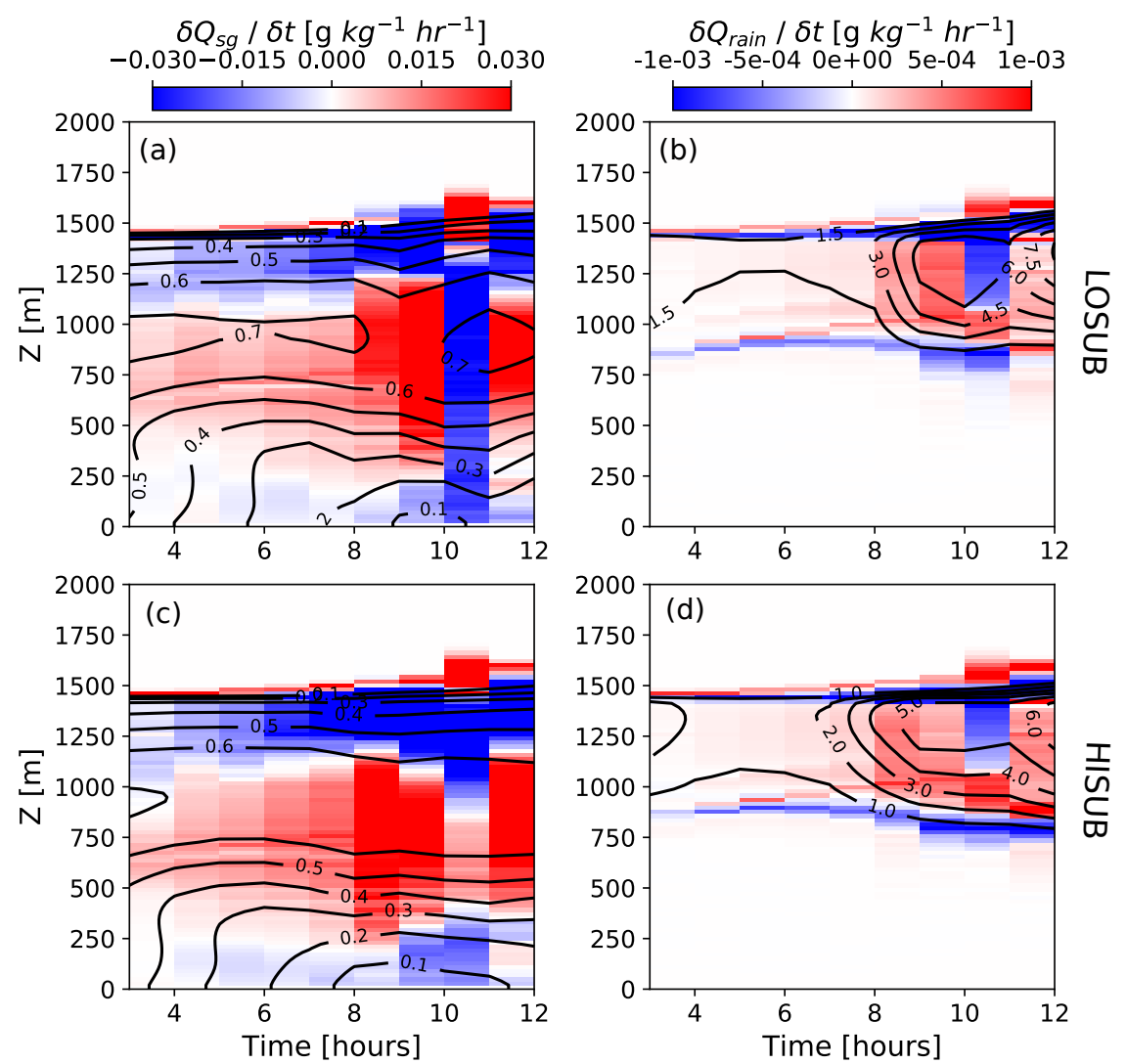

Figure S9. Arranged similarly to Fig. 5, showing the comparison between simulations with a warming surface (test 4). 

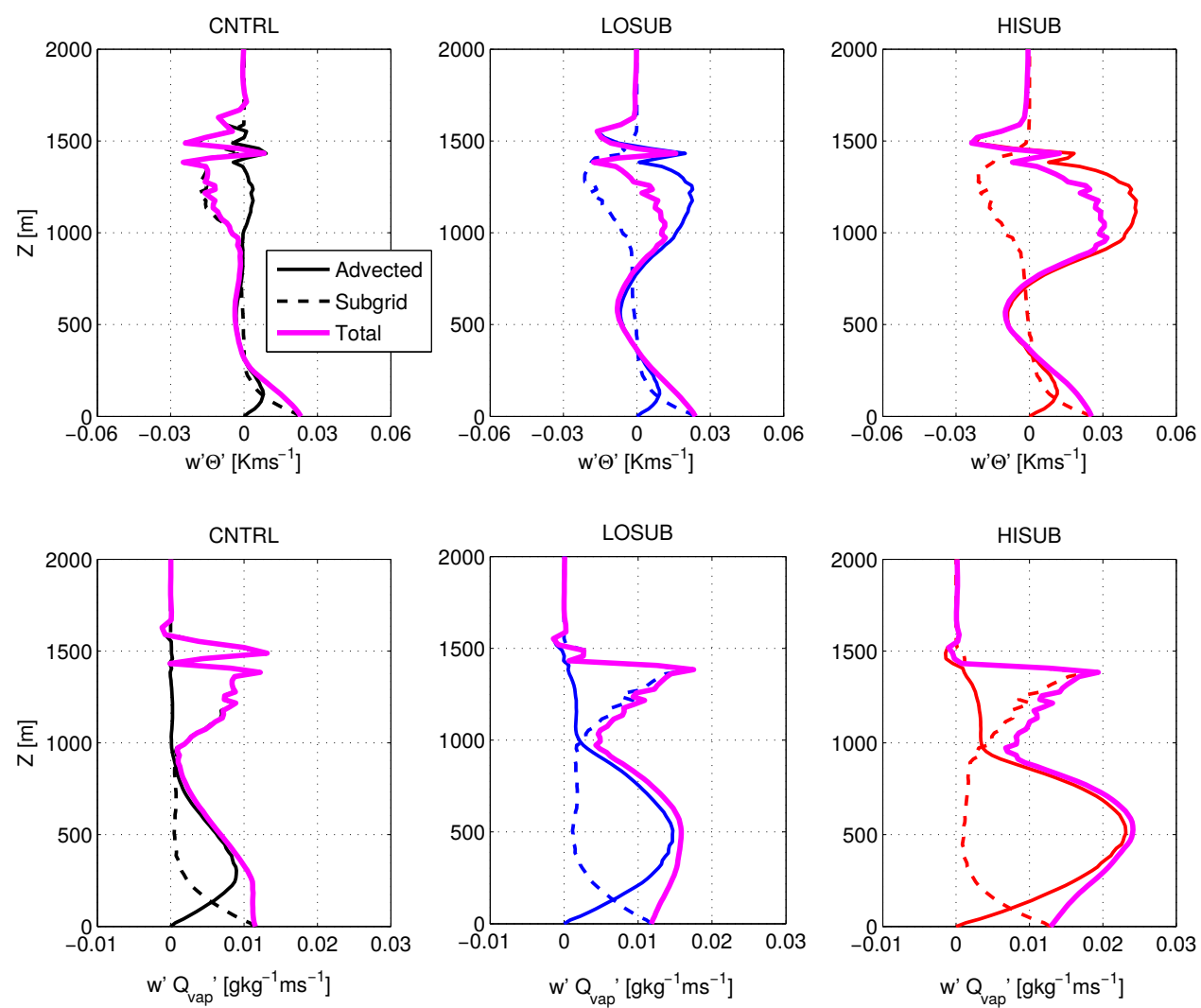

Figure S10. Relative contribution of advected (solid) and sub-grid (dashed) fluxes to the total (solid, magenta), w' $\Theta$ ' (top row), and w' $\mathrm{Qvap}^{\prime}$ at $11 \mathrm{~h}$ in test 6 (with surface forcing). 